\title{
Recursos naturais e agricultura: Um estudo no município de Balsas a partir dos dados do cadastro ambiental rural
}

Natural resources and agriculture: A study in the city of Balsas from the rural environmental registry data

Recursos naturales y agricultura: Un estudio en el municipio de Balsas a partir de datos del registro ambiental rural

Marcos Antônio Pereira da Fonseca Maltez ORCID: https://orcid.org/0000-0003-0941-8051 Universidade Federal Rio Grande do Sul, Brasil E-mail: marcos.maltez@biocitrus.com.br

Leonardo França da Silva

ORCID: https://orcid.org/0000-0002-9710-8100 Universidade de Federal Viçosa, Brasil E-mail: leonardo.silva@ufv.br

Mateus Lauar de Melo

ORCID: https://orcid.org/0000-0003-1808-1868 Universidade de Federal Viçosa, Brasil

E-mail:mateus.lauar@hotmail.com

Maria Fernanda Antunes Collares ORCID: https://orcid.org/0000-0003-3111-5380 Universidade de Federal Viçosa, Brasil E-mail:maria.collares@ufv.br

Maria Angela de Souza

ORCID: https://orcid.org/0000-0002-1061-3340 Universidade de Federal Viçosa, Brasil E-mail: maria.a.souza@ufv.br

Victor Crespo de Oliveira

ORCID: https://orcid.org/0000-0003-2719-9972 Universidade de Federal Viçosa, Brasil E-mail: victor.oliveira1@ufv.br

Fabiane de Fátima Maciel

ORCID: https://orcid.org/0000-0002-7117-6965 Universidade de Federal Viçosa, Brasil

E-mail: fabiane.maciel@ufv.br

Bianca Moreira Vicente

ORCID: https://orcid.org/0000-0003-1738-2933 Universidade de Federal Lavras, Brasil E-mail: biancamvicente.14@gmail.com

Bruna Nogueira Rezende

ORCID: https://orcid.org/0000-0003-4337-9324

Universidade de São Paulo, Brasil E-mail: bbrunarezende@ hotmail.com

\section{Resumo}

O Cadastro Ambiental Rural (CAR) é um registro eletrônico obrigatório para todos os imóveis rurais brasileiros, esse registro tem como finalidade monitorar e fiscalizar os recursos naturais relacionados principalmente a vegetação e os recursos hídricos. Os dados estão disponíveis, em sites públicos, para download. Este trabalho utilizou os dados do CAR para analisar a situação ambiental do município de Balsas no Sul do Maranhão, tendo como classes de análise a vegetação preservada, os imóveis rurais e as nascentes cadastradas. A metodologia aplicada no trabalho foi em parte construída pela EMBRAPA, e permitiu apresentar os dados do município de forma cartografada, quantificada e qualificada. O município de Balsas apresenta um total de 2.272 imóveis cadastrados, contém 39,5 \% da sua vegetação preservada e um total de 345 nascentes. A partir dos resultados dessa pesquisa infere-se que o município cumpre com o estabelecido na legislação ambiental.

Palavras-chave: CAR; Balsas/MA; Geoprocessamento. 


\begin{abstract}
The Rural Environmental Registry (CAR) is a mandatory electronic record for all Brazilian rural properties, this record is intended to monitor and inspect natural resources mainly related to vegetation and water resources. The data is available for download on public websites. This work used the CAR data to analyze the environmental situation of the municipality of Balsas in the south of Maranhão, having as classes of analysis the preserved vegetation, the rural properties and the registered springs. The methodology applied in the work was partly built by EMBRAPA, and allowed to present the data of the municipality in a mapped, quantified and qualified way. The municipality of Balsas has a total of 2,272 registered properties, contains $39.5 \%$ of its preserved vegetation and a total of 345 springs. From the results of this research, it can be inferred that the municipality complies with the requirements of environmental legislation.
\end{abstract}

Keywords: CAR; Balsas/MA; Geoprocessing.

\title{
Resumen
}

El Registro Ambiental Rural (CAR) es un registro electrónico obligatorio para todas las propiedades rurales brasileñas, este registro está destinado a monitorear e inspeccionar los recursos naturales relacionados principalmente con la vegetación y los recursos hídricos. Los datos están disponibles para su descarga en sitios web públicos. Este trabajo utilizó los datos del CAR para analizar la situación ambiental del municipio de Balsas en el sur de Maranhão, teniendo como clases de análisis la vegetación preservada, las propiedades rurales y los manantiales registrados. La metodología aplicada en el trabajo fue construida en parte por EMBRAPA, y permitió presentar los datos del municipio de forma mapeada, cuantificada y calificada. El municipio de Balsas tiene un total de 2.272 predios registrados, contiene el $39.5 \%$ de su vegetación preservada y un total de 345 manantiales. De los resultados de esta investigación se puede inferir que el municipio cumple con los requisitos de la legislación ambiental.

Palabras clave: CAR; Balsas/MA; Geoprocesamiento.

\section{Introdução}

Os recursos naturais são fundamentais para a existência da humanidade e de outros seres vivos, fatos que por si só mostram a importância de sua preservação. A sua utilização permitiu o desenvolvimento de produtos e objetos essenciais para a sociedade contemporânea. De acordo com o site governamental, o Cadastro Ambiental Rural (CAR) foi criado pela lei n ${ }^{\circ}$ 12.651/2012 (BRASIL, 2012), no âmbito do Sistema Nacional de Informação sobre Meio Ambiente - SINIMA, e regulamentado pela Instrução Normativa MMA no 2/2014 é:

\footnotetext{
"Um registro público eletrônico de âmbito nacional, obrigatório para todos os imóveis rurais, com a finalidade de integrar as informações ambientais das propriedades e posses rurais referentes às Áreas de Preservação Permanente APP, de uso restrito, de Reserva Legal, de remanescentes de florestas e demais formas de vegetação nativa, e das áreas consolidadas, compondo base de dados para controle, monitoramento, planejamento ambiental e econômico e combate ao desmatamento" (CAR, s.d.)
}

Nesse contexto, o CAR pode ser considerado como importante ferramenta na promoção do desenvolvimento rural sustentável, pois constitui um importante instrumento para o planejamento agrícola, ambiental e econômico para o Brasil (BRASIL, 2012). O cadastro ambiental rural disponibiliza as informações cadastradas, onde essas informações são georreferenciadas e apresentadas em formato Shapefile por meio de pontos linhas e polígonos. Assim, as informações são analisadas por diferentes instituições públicas e/ou privadas. Em especial, o Grupo de Inteligência Territorial (GITE), ligado a Empresa Brasileira de Pesquisa Agropecuária (EMBRAPA), vem desenvolvendo metodologias de tratamento e análise de dados do CAR (Neto, Rosa; 2018; Silva et. al., 2021; Faria et. al., 2018).

O Geoprocessamento pode ser definido como um conjunto de técnicas computacionais que operam sobre base de dados georreferenciados, para assim, os transformar em informação (Silva, 2001; Silva et. al., 2021). Utiliza-se de um conjunto de conceitos, métodos e técnicas para coletar e tratar informações georreferenciadas, e permitir o desenvolvimento constante de novas aplicações. A polivalência da tecnologia do geoprocessamento faz com que a mesma possua várias aplicações, sendo a parte de análise ambiental a que mais se apropriou dessa tecnologia. A obtenção de mapas com rapidez, qualidade e precisão, além do acesso a diferentes bancos de dados, transformou o geoprocessamento em uma importante ferramenta no estudo sobre 
o meio ambiente (Silva, 2004; Silva et. al., 2021; Moratori, Faria, 2020; Rocha, Santos, 2019).

O município de Balsas, localizado no sul do Maranhão, tem sua história marcada pela agricultura e pecuária que aconteceram de forma dessemelhante e em tempos diferentes. Até a década de 70 manteve-se a criação de gado de forma extensiva e a produção diversificada de alimentos. Com a chegada dos "gaúchos" deu-se início aos monocultivos de soja, milho e algodão (IBGE,2017). A região também foi alvo de vários projetos de desenvolvimento do cerrado, que incentivaram a produção de commodities, como o PRODECER que financiou a compra de grandes fazendas no município.

Balsas mantém-se como um importante município no panorama da produção agropecuária do Brasil, sendo que a sua economia é majoritariamente voltada para a produção de commodities. Em 2017, a produção de soja foi de 505.289 toneladas, quantidade significativa quando comparada a produção de toda a região norte que foi de 8.681 .570 toneladas (IBGE, 2017).

Com base nos dados do SICAR e na legislação ambiental brasileira, o objetivo desse trabalho foi realizar análise da situação das áreas de preservação ambiental e das nascentes do município de Balsas-MA.

\section{Metodologia}

Esse Parte dos procedimentos metodológicos desse trabalho teve embasamento na metodologia desenvolvida pelo Grupo de Inteligência Territorial Estratégica (GITE) da Empresa Brasileira de Agropecuária (EMBRAPA) (Miranda et al., 2016; Silva, 2021). Alguns ajustes e complementações foram necessárias devido às diferenças de abrangência do estudo e dos objetivos propostos. O município de Balsas foi escolhido como área de estudo devido a sua importância na produção agrícola do Brasil e pelo tipo de agricultura praticada no município, sua localização pode ser observada na Figura 1.

Figura 1. Localização da área de estudo Município de Balsas-MA.

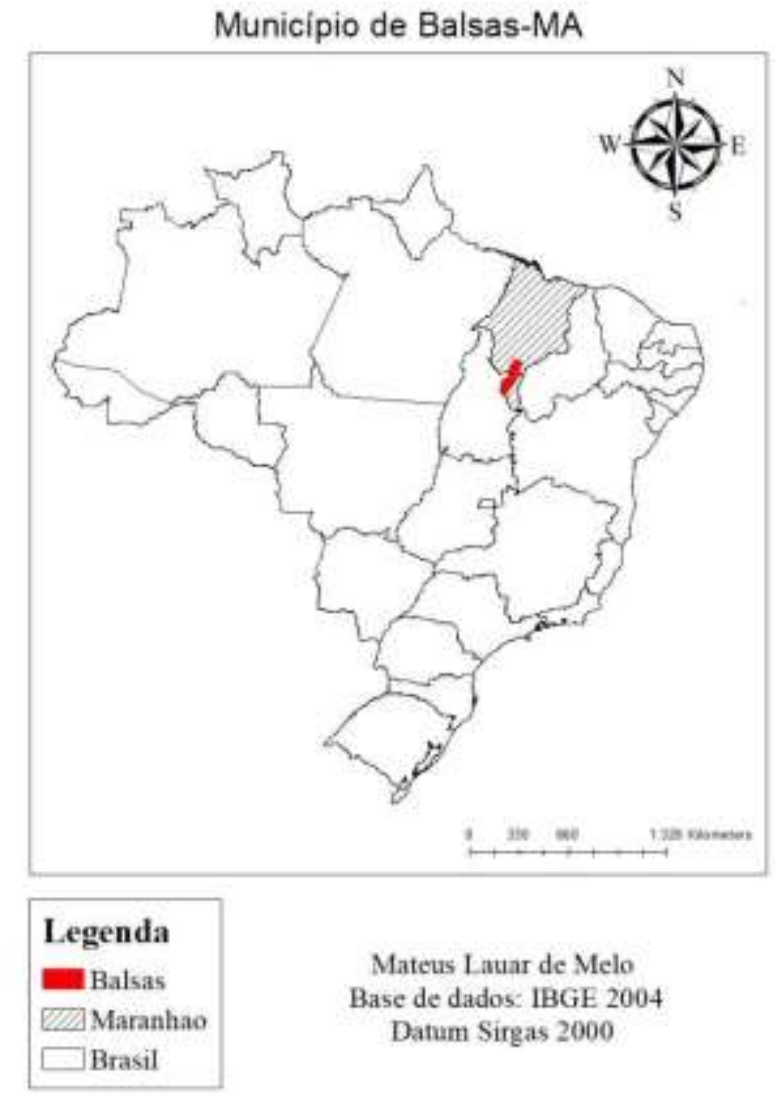

Fonte: Autores. 


\section{Coleta de dados}

Os dados foram coletados de três diferentes bases de dados:

SICAR: os dados estão disponíveis no site "www.car.gov.br/publico/imoveis", em formato Shapefile, separados por munícipios. Ao todo são disponibilizadas 18 categorias de uso e ocupação de terras geocodificadas, as quais estão representadas por polígonos, pontos e linhas. Para o presente artigo, utilizaram-se as categorias: Área do Imóvel, Nascentes, APP, Vegetação Nativa e Reserva Legal;

IBGE: os dados referentes a separação político-administrativa do município e do Maranhão são do site “www.ibge.com.br";

TOPODATA: o download dos arquivos em formato raster, para o mapa de declividade, é proveniente do site da EMPRABA/CNPTIA “www.topodata.com.br”.

\section{Processamento de dados}

O processamento dos dados foi feito com o software de geoprocessamento ArcGis 10.5.

A integração dos arquivos em um único plano de informações foi realizada com a função "União" do software ArcGis a qual permite que todas as informações dos municípios se concentrem em arquivos distintos. As categorias APP, Vegetação Nativa e Reserva Legal foram transformadas em um mesmo arquivo Shapefile. Já as categorias Nascentes e Área do Imóvel foram unidas em um único arquivo que abrangia toda a área de estudo, tal como pesquisa realizada por Miranda et al., 2016.

\section{Exclusão de arquivos espúrios}

Os dados do SICAR são auto declaratórios e, por vezes, apresentam arquivos espúrios como: imensas propriedades, cadastros de partes de rios, parques e reservas. Esses arquivos serão selecionados pela "tabela de atributos" e em seguida excluídos (MIRANDA et al., 2016).

\section{Eliminação das sobreposições dos imóveis rurais}

Os polígonos dos imóveis rurais possuem algumas sobreposições. Para eliminá-las, a ferramenta "Dissolve" será aplicada sobre os dados. Essa operação consiste em um procedimento sobre dados vetoriais, onde as fronteiras entre as feições são eliminadas de modo a formarem uma única entidade (MIRANDA et al., 2016).

\section{Interseção dos imóveis rurais com os municípios}

Os polígonos dos imóveis rurais são os mais importantes, já que delimitam outros dados, porém alguns imóveis rurais se localizam nas divisões municipais. Para definição do município que o imóvel rural pertence foi utilizada a função "Interseção" a qual delimitou a área de estudo (MIRANDA et al., 2016).

\section{Dissolução dos arquivos (APP, Vegetação Nativa e Reserva Legal)}

A função "União" foi utilizada para mesclar as categorias APP, Vegetação Nativa e Reserva Legal em um único arquivo, abrangendo, assim, toda área de estudo e toda a área de vegetação preservada. A função "Dissolve" foi utilizada para excluir possíveis sobreposições dos arquivos Shapefiles (MIRANDA et al., 2016).

\section{Qualificação dos imóveis rurais}

Para a divisão dos imóveis rurais, na "tabela de atributos" do arquivo "área dos imóveis rurais" selecionou-se a função "Partir de Equação", em três classes: 1) áreas menores ou iguais a 4 módulos fiscais $(<1)$, sendo essas considerado imóveis 
familiares, 2) áreas entre 4 e 15 módulos fiscais $(>4,<15)$ sendo considerados media propriedade; e 3) áreas acima de 15 módulos fiscais (>15), sendo considerados grandes propriedades (Tabela 1). Esses três arquivos foram utilizados para o recorte da vegetação preservada e nascentes, e também para sobrepor os imóveis rurais sobre o mapa de declividade da área de estudo.

Tabela 1. Divisão dos imóveis rurais a partir dos módulos fiscais.

\begin{tabular}{cl}
\hline Unidade familiar & Entre 0 e 4 módulo(s) fiscal \\
\hline Média propriedade & Entre 4 e 15 módulos fiscais \\
\hline Grande propriedade & Acima de 15 módulos fiscais \\
\hline
\end{tabular}

Fonte: Autores.

\section{Quantificação dos dados}

Após a geração dos mapas foi possível quantificar, em hectares, as categorias estudadas (área do imóvel e área de vegetação preservada) e, em número, a nascentes.

\section{Diferenciação da área de APP, Reserva legal e Vegetação Nativa}

Para separar as áreas de APP, Reserva Legal e Vegetação nativa foi necessário o recorte das áreas. O artigo $15^{\circ}$ da Lei n o 12.651/2012 prevê que:

"O cômputo das Áreas de Preservação Permanente no cálculo do percentual da Reserva Legal do imóvel, desde que: I - o benefício previsto neste artigo não implique a conversão de novas áreas para o uso alternativo do solo; II - a área a ser computada esteja conservada ou em processo de recuperação, conforme comprovação do proprietário ao órgão estadual integrante do Sisnama; e III - o proprietário ou possuidor tenha requerido inclusão do imóvel no Cadastro Ambiental Rural - CAR" (BRASI, 2012).

Sendo assim, realizou-se o recorte da classe APP e Vegetação Nativa com a reserva legal, gerando as áreas exclusivas dessas classes. Para chegar a área total exclusiva de reserva legal o arquivo foi recortado com as classes APP e vegetação nativa, o que gera um arquivo contendo a área de reserva legal.

\section{Resultados e Discussão}

\section{Imóveis rurais}

O município de Balsas possui 2.272 imóveis rurais cadastrados que ocupam uma área total de 1.028.092,9 hectares. A análise da distribuição fundiária do município demonstra o domínio dos grandes imóveis rurais, que apesar de serem a categoria com menor números de imóveis, ocupam mais da maior parte do município. O maior imóvel rural registrado tem um total de 603 e o menor 0,125 módulos fiscais. A distribuição dos imóveis rurais no município de Balsas pode ser observada na Figura 2.Os dados do SICAR (2017), que foram utilizados nesse mapa já estão tratados e delimitados, ao todo o processo de tratamento dos dados excluiu 24 imóveis rurais, esses estavam irregulares ou mal cadastrados. 
Figura 2. Distribuição dos imóveis rurais em Balsas-MA.

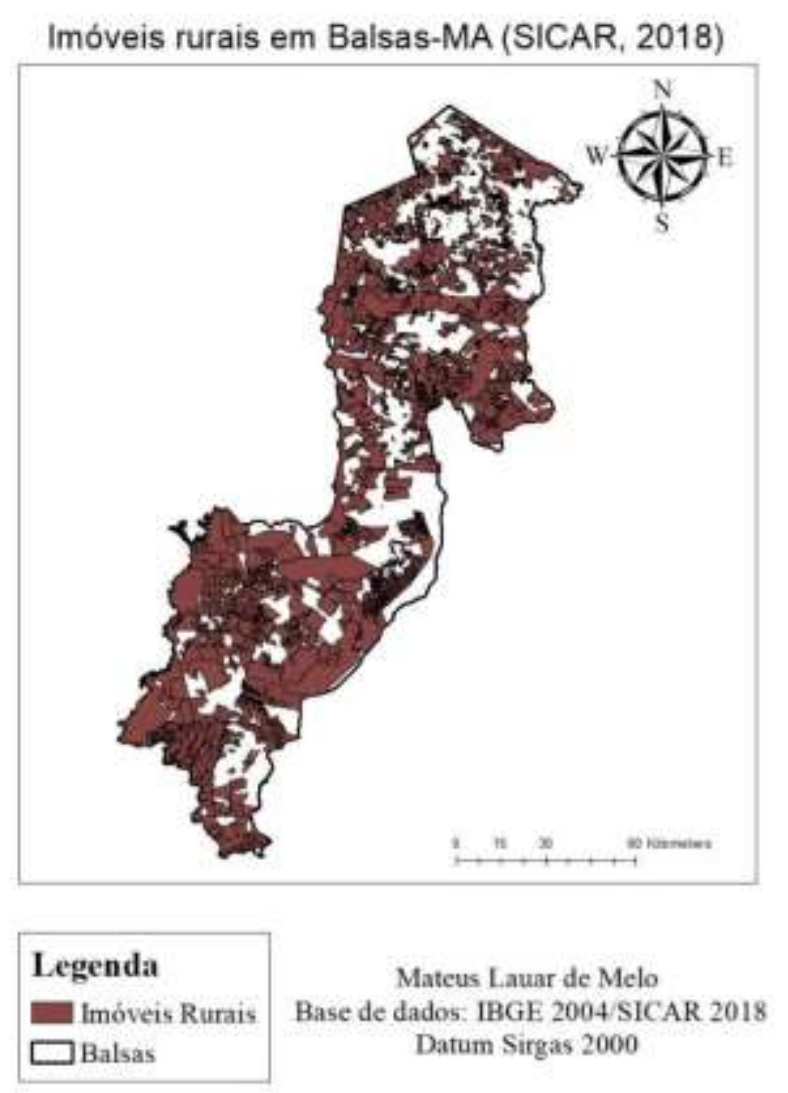

Fonte: Autores.

Ao sudoeste do mapa é possível notar a presença de assentamentos dos programas de desenvolvimento do Cerrado, principalmente o Proceder. As grandes fazendas se ocupam principalmente com a produção de commodities. O município é o principal produtor de soja e milho do Estado do Maranhão, atingindo uma produção total de 300 toneladas de milho e 501.668 toneladas de soja. O município ainda produz 47.644 toneladas de algodão e 3.391 toneladas de feijão (IBGE, 2015).

A quantificação dos imóveis rurais está apresentada na Tabela 2, nota-se que na distribuição fundiária do município de Balsas existem 178 grandes imóveis rurais cadastrados no município, o que representa 8\% do total dos imóveis rurais. Das três classes pesquisadas esse é o tipo de imóvel com menor representatividade em número e com maior representatividade em área, sendo 693.673,00 hectares de terra que representa 76\% do total da área cadastrada.

Já os imóveis médios têm 376 propriedades que representam 21\% do total de imóveis rurais cadastrados e 216.619,9 hectares representando $16 \%$ do total da área agrícola. De acordo com o levantamento, há um maior número de imóveis rurais pertencentes a agricultores familiares sendo um total de 1.718 propriedades que representam $76 \%$ do total de imóveis cadastrados e 118.800,0 hectares ocupando $12 \%$ da área total destinada a agropecuária.

Tabela 2. Qualificação dos imóveis rurais na área de estudo.

\begin{tabular}{ccccc}
\hline Tipo de Imóvel & $\begin{array}{c}\text { Quantidade de } \\
\text { imóveis }\end{array}$ & $\begin{array}{c}\text { Área } \\
\text { (hectares) }\end{array}$ & $\begin{array}{c}\text { \% de ocupação da } \\
\text { área }\end{array}$ & $\begin{array}{c}\% \text { de imóveis } \\
\text { rurais }\end{array}$ \\
\hline Imóveis Familiares & 1718 & 118800,0 & $12 \%$ & $76 \%$ \\
Imóveis Médios & 376 & 216619,9 & $21 \%$ & $16 \%$ \\
Imóveis Grande & 178 & 692673,0 & $67 \%$ & $8 \%$ \\
Total & 2272 & $1.028 .092,9$ & $100 \%$ & $100 \%$ \\
\hline
\end{tabular}

Fonte: Autores (2018). 


\section{Vegetação preservada}

A área de vegetação preservada foi formada a partir da união de três classes utilizadas no CAR: área de vegetação nativa, área de preservação permanente e reserva legal. Nesse artigo, a soma dessas classes representa a quantidade em área de vegetação preservada presente nos imóveis rurais. A dimensão cartográfica da área de vegetação preservada nos imóveis rurais está representada na Figura 3, a área de cor verde representa a vegetação preservada, e a área de cor marrom outros tipos de áreas dentro dos imóveis (área consolidada, interesse público, sede e infraestrutura).

Figura 3. Distribuição da área de vegetação preservada em Balsas - MA.

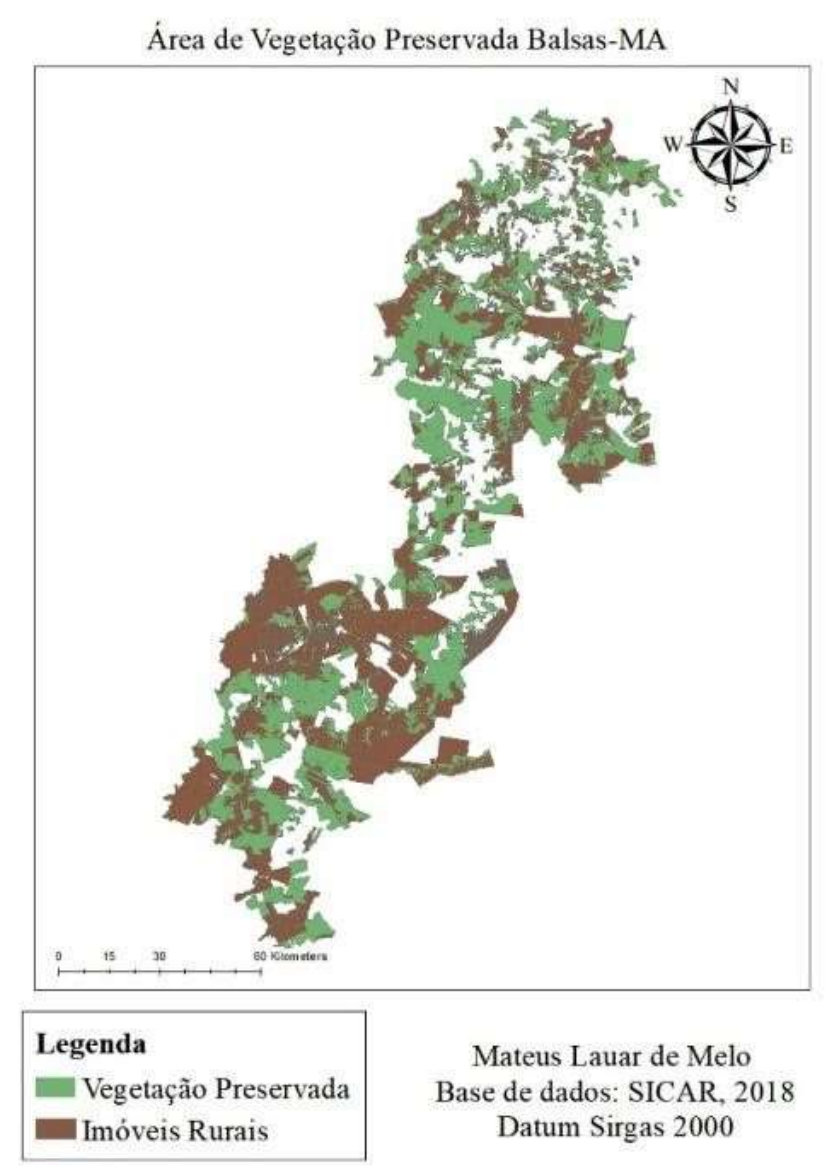

Fonte: Autores.

Balsas possui 409.467 hectares de vegetação preservada cadastrados no SICAR (2018), o que representa 39,5\% da área total cadastrada do município. Pela lei do código florestal o município não apresenta déficits de vegetação, já que área obrigatória a ser destinada a reserva legal total de cada imóvel rural é de 35\%. A análise dos dados permite uma avaliação geral da presença da vegetação preservada do município, como pode-se verificar nos mapas apresentados na Figura 4. Análise detalhada para cada imóvel demandaria uma pesquisa mais extensa, já que no município existem 2272 imóveis rurais. 
Figura 4. Divisão da área de vegetação preservada em Balsas-MA.

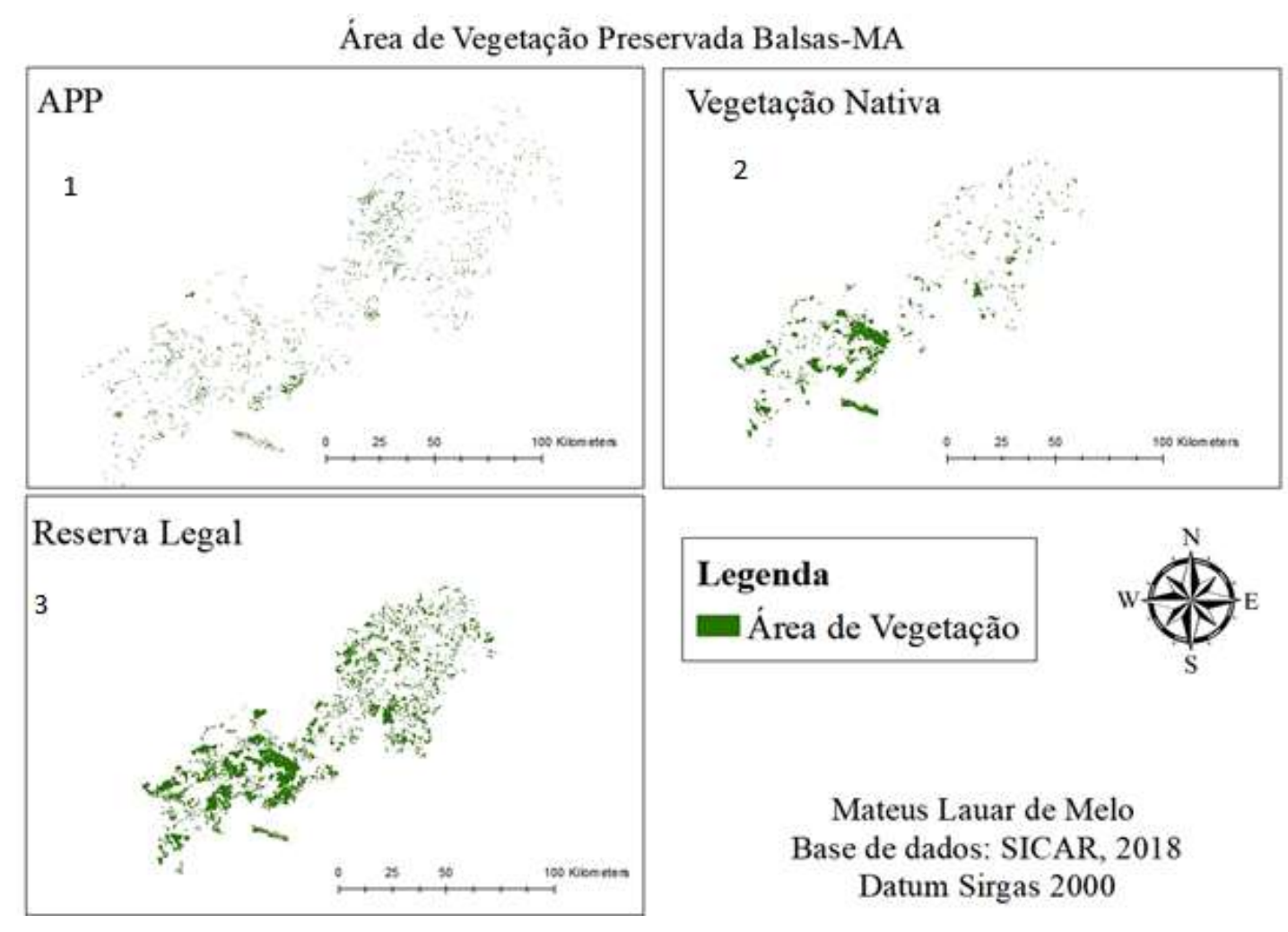

Fonte: Autores.

Para o cálculo da área de vegetação foi necessário trabalhar com as classes de forma separada, já que pelo novo código florestal as áreas de APP e áreas de vegetação nativa podem ser cadastradas como áreas de reserva legal, o que por vezes gera áreas sobrepostas de vegetação, sendo necessário o recorte dessas áreas. Após o processo de recorte foi possível calcular e cartografar as áreas de APP, Reserva Legal e Área de Vegetação Nativa de forma separada. A área de APP apesar de ser a classe com maiores números de área cadastrada é a que tem a menor área total em hectares, a área de Reserva Legal é a classe tem que maior número em hectares cadastrados, seguido pela vegetação nativa.

Na Figura 4 a APP, representada no quadrante 1, possui 48.215 hectares e representa 11,79\% da área total cadastrada. No quadrante 2, a área de vegetação nativa com 108.973 hectares representa 26,61\% do total. No quadrante 3 está a reserva legal com 252.454 hectares, é a área cadastrada com maior extensão e representa 61,12\% do total registrado no SICAR em 2018. A divisão da área de vegetação preservada entre os diferentes tipos de imóveis rurais analisados é demonstrada na Figura 5. A cor verde representa a área de vegetação preservada e a cor marrom representa outros tipos de áreas (área consolidada, interesse público, sede e infraestrutura). Os imóveis grandes são os que ocupam a maior parte da área do município e consequentemente detém a maior área de vegetação preservada, seguido pelos imóveis médios e familiares. Os imóveis grandes possuem maior área de vegetação preservada quando comparado ao total de área do município, porém possuem menor porcentagem de área preservada quando comparados individualmente com outras propriedades de tamanhos inferiores. 
Figura 5. Área vegetação preservada sobres os Imóveis Rurais.

Area de vegetação preservada sobres os Imóveis Rurais - Balsas-MA
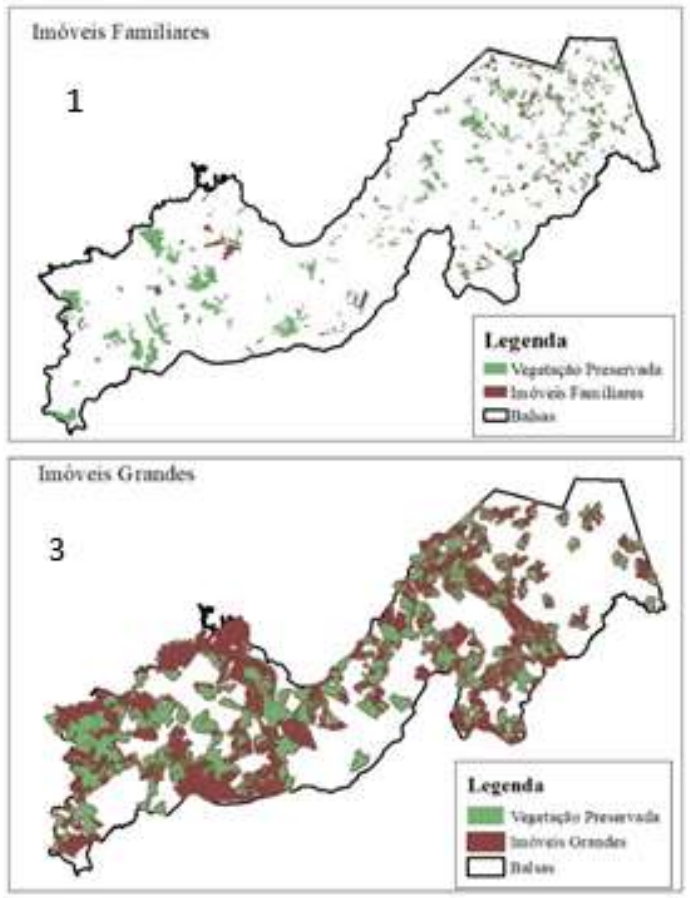
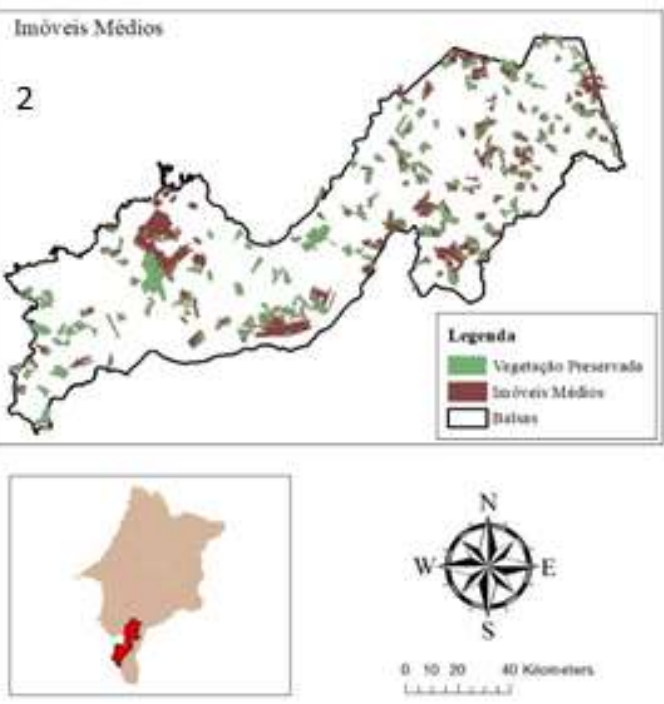

Matens L.auar de Melo

Base de dados: SICAR 2017/IBGE 2004 Datuin Sirgas 2000

Fonte: Autores.

Os imóveis familiares, no quadrante 1, são responsáveis pela preservação de 118.800 hectares de vegetação que representa $48 \%$ da sua área total do município. A agricultura familiar praticada em Balsas tem uma produção diversificada, sendo os principais cultivos: mandioca, banana, feijão, inhame, melancia, hortaliças e verduras. A alta porcentagem de preservação da agricultura familiar corrobora com diversos estudos que afirmam o importante papel dessa categoria na preservação ambiental. O Quadrante 2 apresenta 82.542 ha de área de vegetação preservada nos imóveis médios que representa $38 \%$ da área total ocupada por essas propriedades. Os imóveis médios têm produção voltada para a soja e milho, porém, em menores proporções quando comparados aos imóveis grandes. A área de vegetação preservada por imóveis grandes está representada no quadrante 4, essa categoria tem 269.898 hectares, que representa $39 \%$ da área total ocupada por essas propriedades.

\section{Nascentes}

O município de Balsas tem importante papel na segurança hídrica de grande parte dos municípios do sudoeste do Maranhão, na Figura 6 é apresentado as nascentes do município de Balsas cadastradas no SICAR-2018, totalizando 345 nascentes. Os principais afluentes do rio Balsas são os rios Maravilha, Neves, Tem-Medo, do Peixe e Surucujo. 
Figura 6. Nascentes municípios de Balsas-MA.

Nascente municipios de Balsas-MA

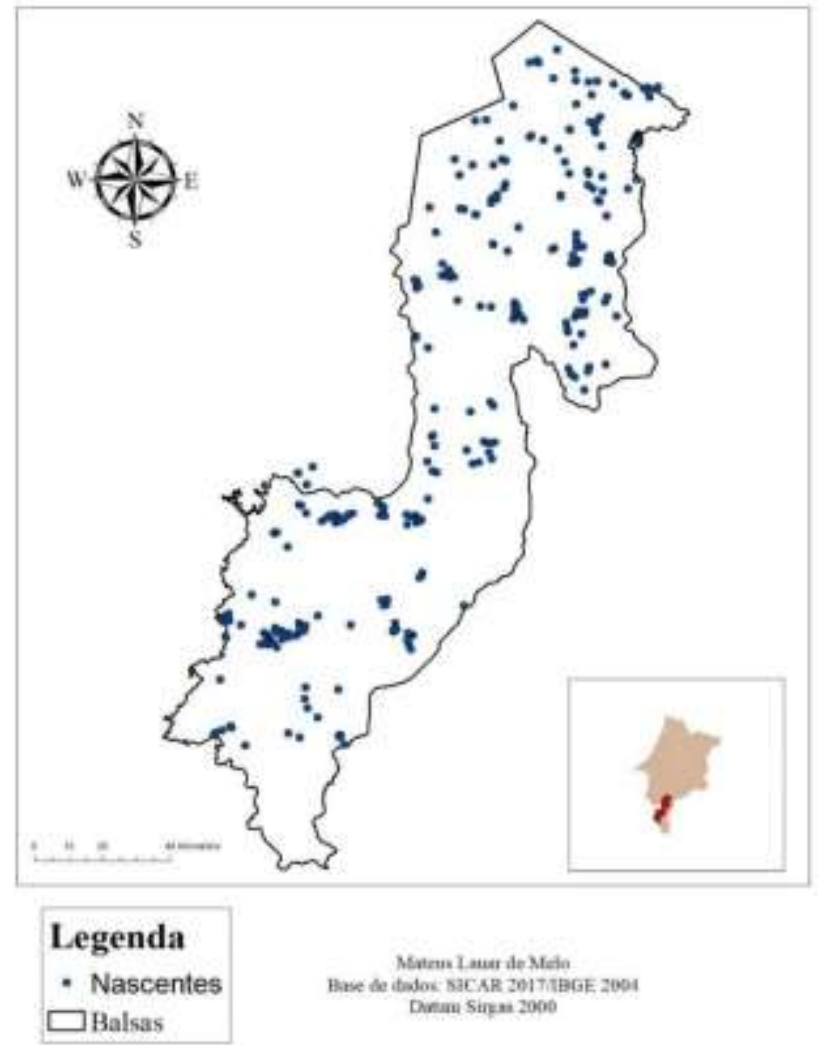

Fonte: Autores.

O município apresenta extensas chapadas que são cortadas por profundos vales e as nascentes tendem a se concentrar em áreas mais declivosas. Áreas de chapada é importante no cerrado, pois funcionam como grandes caixas d’água, sendo responsáveis por armazenar água e liberá-la de forma gradual durante o ano para as nascentes presentes nos vales (SILVA, 2008). A Figura 7, apresenta a distribuição das nascentes sobre a declividade do município de Balsas, a área com tons verdes são áreas planas que tem declividade entre 0 e $20 \%$ e as áreas com tons avermelhados são mais declivosas e tem entre 20 $100 \%$ de declividade. Essas áreas apresentam vegetação diferente das chapadas, as arvores tem maior porte e a vegetação é mais adensada. A área de preservação permanente delimitada pelo código florestal para nascentes é de 50 metros de diâmetro ou 2.000 metros quadrados. Essa área de APP é de extremamente importante para as nascentes pois podem garantir melhor qualidade e quantidade da água da nascente. 
Figura 7. Mapa de declividade com distribuição das nascentes no município de Balsas-MA.

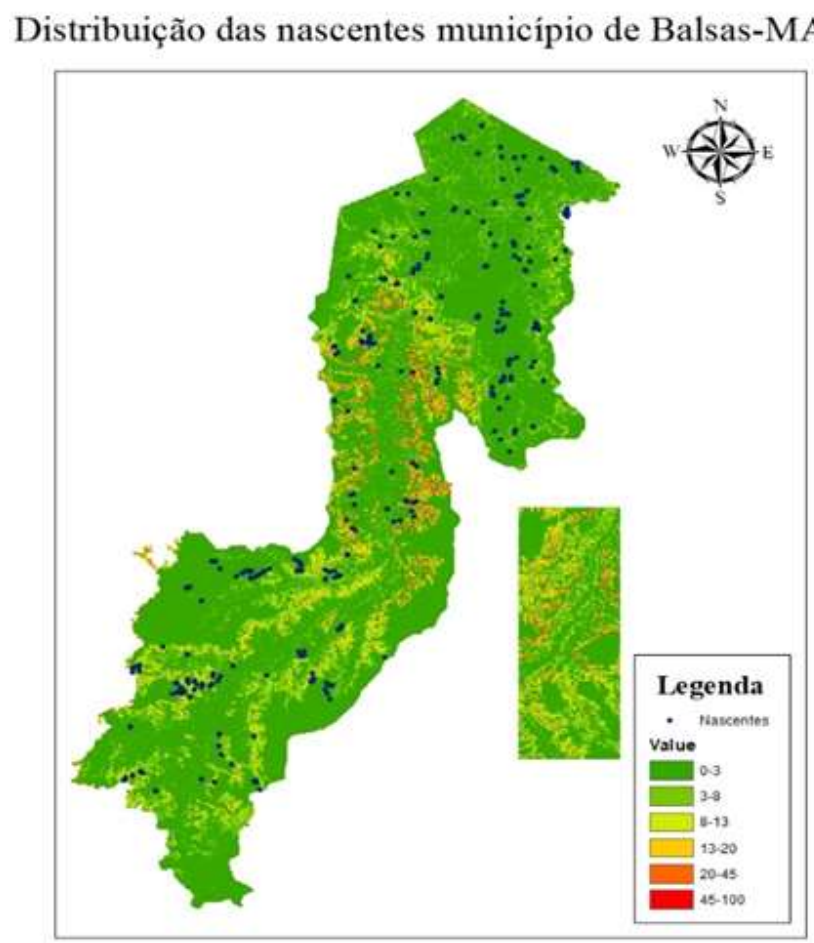

Fonte: Autores.

A divisão das nascentes por categoria de imóvel rural está representada na Figura 8.

Figura 8. Nascentes sobre os imóveis rurais de Balsas-MA.

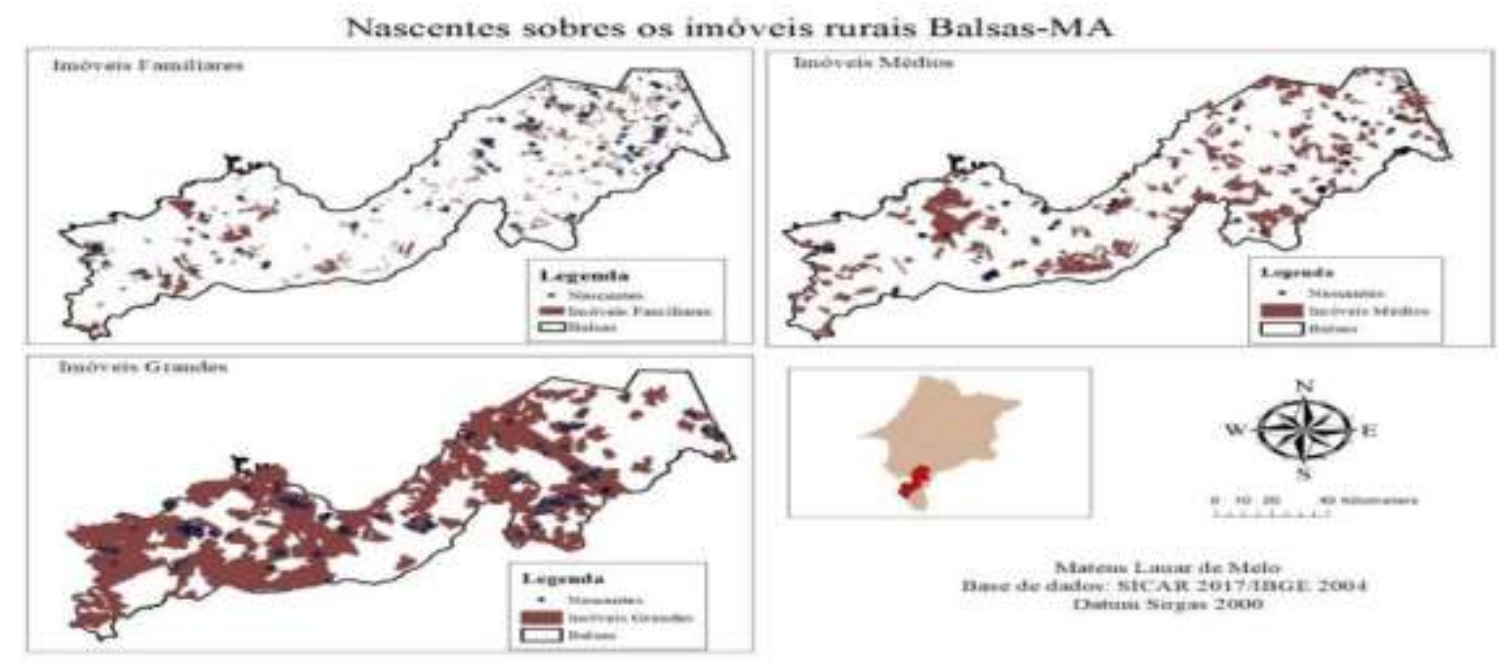

Fonte: Autores.

A categoria imóveis grandes é a que apresenta maior quantidade de nascentes em sua área. Fato esperado visto que essa ocupa $67 \%$ da área do município de Balsas. A categoria tem 155 nascentes o que representa 44\% do total de nascentes no município. Pela lógica, era de se esperar que os imóveis médios apresentassem a segunda maior quantidade em nascentes, porém, a agricultura familiar do município de Balsas tem em seu território 129 nascentes o que representa 38\% do total. Esse fato pode ser explicado pela localização dos imóveis familiares, que, em geral, estão dentro ou tem parte do imóvel dentro dos 
vales, áreas que tendem a concentrar as nascentes do cerrado. Os imóveis médios detêm 61 nascentes que representa $18 \%$ do total.

\section{Considerações Finais}

O CAR foi instituído com o objetivo de integrar o planejamento econômico e ambiental dos imóveis rurais brasileiros. Ele pode auxiliar na fiscalização da preservação de florestas e demais formas de vegetação nativa, e assim, colaborar para a redução do desmatamento em áreas que devem ser protegidas. O SICAR (2018) disponibiliza importantes dados georreferenciados que podem ser trabalhados a partir de diferentes abordagens e metodologias. A intensificação da agropecuária na região ocasionou uma concentração fundiária para a minoria. Dessa forma, 178 imóveis rurais detém um total de 64\% da área do município, enquanto 1.712 imóveis rurais ocupam 12\% da área.

Praticamente toda a extensão do município de Balsas está cadastrada no SICAR (2018), demonstrando bom resultado na implantação do cadastro ambiental rural no município. A área de reserva legal de todas as categorias de imóveis rurais analisados (familiar, médio e grande) através de dados disponíveis no SICAR em 2018 estão de acordo com a legislação ambiental vigente. Em relação as nascentes do município, verificou-se que os imóveis grandes apresentaram a maior porcentagem em seu território (44\%). Contudo, diferentemente do esperado a quantidade de nascentes nos imóveis familiares (38\%) foi maior que nos imóveis médios $(18 \%)$.

\section{Referências}

Aparecido, W. A. S. (2021). Mapa da vegetação nativa declarada no Cadastro Ambiental Rural-CAR em Montes Claros-MG. Revista Verde Grande: Geografia e Interdisciplinaridade, 3(01), 151-175.

Brasil. (2012). Decreto n ${ }^{\circ}$ 7.830, de 17 de outubro de 2012. Dispõe sobre o Sistema de Cadastro Ambiental Rural, o Cadastro Ambiental Rural, estabelece normas de caráter geral aos Programas de Regularização Ambiental, de que trata a Lei n o 12.651, de 25 de maio de 2012 , e dá outras providências. CAR. (2019). Cadastro Ambiental Rural. Website do Serviço Florestal Brasileiro. //www.car.gov.br/\#/sobre.

da Rocha, V. N. L., \& dos Santos, A. L. S. (2019). Cadastro Ambiental Rural (CAR) e municípios costeiros maranhenses: análise dos dados autodeclarados. Revista Ibero-Americana de Ciências Ambientais, 10(4), 328-336.

da Silva, J. X. (2001). Geoprocessamento para análise ambiental. J. Xavier da Silva.

da Silva, L. F., da Fonseca Maltez, M. A. P., da Silva, E. P. F., de Credo Assis, K. C., Begueline, M. C. L. M., \& Rezende, B. N. (2021). Mapeamento das classes do cadastro ambiental rural (CAR) De imóveis rurais familiares e não familiares nas chapadas e grotas do alto Jequitinhonha-MG. Holos Environment, 21(1), 160-172.

de Almeida Moratori, D., \& de Faria, S. H. (2020). O patrimônio cultural sobre um viés cartográfico: a utilização de ferramentas de geoprocessamento para reconhecer e revalorizar o patrimônio edificado de Juiz de Fora/MG-Cultural Heritage under a cartographic bias: the use of geoprocessing tools to... Multiverso: Revista Eletrônica do Campus Juiz de Fora-IF Sudeste MG, 5, 465.

Farias, M., Beltrão, N., Santos, C., \& Silva, C. (2018). Potencial do Cadastro Ambiental Rural (CAR) no controle do desmatamento em assentamentos no município de Novo Repartimento (PA). GOT: Revista de Geografia e Ordenamento do Território, (14), 179.

Gaspar Neto, B. S. R. (2018). Cadastro Ambiental Rural (CAR) em três estados brasileiros: uma análise comparativa de suas reservas legais.

IBGE (2018). Cidades. www.ibge.com.br

IBGE (2019). Indicadores IBGE. www.ibge.com.br

Miranda, E. D., Carvalho, C. D., Oshiro, O. T., \& Martinho, P. (2017). Agricultura e Preservação Ambiental no Brasil: Primeira Análise do Cadastro Ambiental Rural. URL https://www. cnpm. embrapa. br/projetos/car.

SICAR- Sistema Nacional De Cadastro Rural (2018). www.car.gov.br/publico/imoveis

Silva, H. G., Figueiredo, N. D., \& Andrade, G. V. D. (2008). Vegetation structure of a cerradão, and the regional heterogeneity of the Cerrado in Maranhão, Brazil. Revista Árvore, 32(5), 921-930.

Silva, J. X. D., \& Zaidan, R. T. (2004). Geoprocessamento e análise ambiental: aplicações. In Geoprocessamento e análise ambiental: aplicações (pp. 363-363). 